\title{
Involvement of the anterior cingulate and frontoinsular cortices in rapid processing of salient facial emotional information
}

\author{
Jin Fan ${ }^{\text {a,b,c,*, Xiaosi Gu }}{ }^{\text {b }}$, Xun Liu ${ }^{\text {b,e }}$, Kevin G. Guise ${ }^{\text {b }}$, Yunsoo Park ${ }^{\text {b }}$, Laura Martin ${ }^{\text {b }}$, Ashley de Marchena ${ }^{\text {b }}$, \\ Cheuk Y. Tang ${ }^{\mathrm{b}, \mathrm{d}}$, Michael J. Minzenberg ${ }^{\mathrm{f}}$, Patrick R. Hof ${ }^{\mathrm{c}}$
}

a Department of Psychology, Queens College, The City University of New York, 65030 Kissena Blvd., Flushing, NY 11367, USA

b Department of Psychiatry, Mount Sinai School of Medicine, One Gustave L. Levy Place, New York, NY 10029, USA

c Department of Neuroscience, Mount Sinai School of Medicine, One Gustave L. Levy Place, New York, NY 10029, USA

d Department of Radiology, Mount Sinai School of Medicine, One Gustave L. Levy Place, New York, NY 10029, USA

e Institute of Psychology, Chinese Academy of Sciences, 4A Datun Road, Chaoyang District, Beijing 100101, China

f Department of Psychiatry, University of California Davis School of Medicine, 4701 X Street, Sacramento, CA 95817, USA

\section{A R T I C L E I N F O}

\section{Article history:}

Received 8 December 2009

Revised 4 September 2010

Accepted 4 October 2010

Available online 16 October 2010

\section{Keywords:}

Anterior cingulate cortex

Emotion

fMRI

Frontoinsular cortex

Priming

\begin{abstract}
A B S T R A C T
The anterior cingulate cortex (ACC) and frontoinsular cortex (FI) have been implicated in processing information across a variety of domains, including those related to attention and emotion. However, their role in rapid information processing, for example, as required for timely processing of salient stimuli, is not well understood. Here, we designed an emotional face priming paradigm and employed functional magnetic resonance imaging to elucidate their role in these mechanisms. Target faces with either neutral or fearful emotion were briefly primed by either neutral or fearful faces, or by blank ovals. The pregenual ACC and the FI, together with other regions, such as the amygdala, were preferentially activated in response to fearful face priming, suggesting that these regions are involved in the rapid processing of salient facial emotional information.
\end{abstract}

(c) 2010 Elsevier Inc. All rights reserved.

\section{Introduction}

Most cognitive neuroscience studies on rapid processing of salient emotions such as fear have mainly focused on the role of the amygdala. Many of these studies are based on animal and lesion models using the fear conditioning paradigm (see LeDoux (2000) for a review). However, the idea that the amygdala is the exclusive region that is essential for unconscious, rapid detection of fear has been challenged. For instance, a recent study found that even with bilateral amygdala lesions, patients could rapidly distinguish fearful faces from faces exhibiting other emotions and rapidly categorize faces as being fearful or neutral (Tsuchiya et al., 2009), as opposed to other studies showing the necessity of an intact amygdala for fearful facial affect recognition (Adolphs et al., 1999). It remains unclear how the brain can still rapidly process salient emotional information in the absence of the amygdala. Thus, the roles of other brain structures and pathways involved in fast emotional processing need to be considered.

A cortical network that consists of the anterior cingulate cortex (ACC) and insular cortex is involved in the control of emotional processing (Bush et al., 2000; Carter et al., 1998; Craig, 2009; Critchley

\footnotetext{
* Corresponding author. Department of Psychology, Queens College, The City University of New York, 65-30 Kissena Blvd., Flushing, NY 11367, USA. Fax: +1 7185700363.

E-mail addresses: jin.fan@qc.cuny.edu, Jin.Fan@mssm.edu (J. Fan).
}

et al., 2004). There are anatomical interconnections between the ACC and amygdala (Paus, 2001) and numerous reciprocal connections among the insular cortex and amygdala (Augustine, 1985; Mufson et al., 1981; Phelps et al., 2001), ACC, other limbic structures, and various regions of the frontal, temporal, and parietal lobes (Augustine, 1985). A role of the insular cortex as a relay to limbic areas has previously been hypothesized (Geschwind, 1965), and is supported by functional imaging studies of empathy (Carr et al., 2003; Gu and Han, 2007; Gu et al., 2010; Jackson et al., 2005; Singer et al., 2004) and lesion studies on the affective component of pain perception and threat-related responses (Berthier et al., 1988). These findings suggest that the ACC and insular cortex play a significant role in emotional response and regulation. However, an overlapping circuitry involving the ACC and insula has also been implicated across a wide variety of cognitive tasks (Nee et al., 2007). Therefore, the role of these structures may relate more to rapid processing of information in general, rather than specifically to emotional processing.

One such piece of evidence for the anatomical specialization of these regions is the presence of large, bipolar, spindle shaped neurons referred to as von Economo neurons (VENs). VENs have previously been described in humans and great apes (Nimchinsky et al., 1999) and have since been described in cetaceans (Butti et al., 2009; Hof and Van der Gucht, 2007) and in elephants (Hakeem et al., 2009). VENs are most abundant in humans and are primarily found in clusters in layer 
$\mathrm{Vb}$ in the ACC with highest densities in areas 24b and 24a, and are also found in a cytoarchitectonically distinct region located in the junction of the posterior orbitofrontal cortex and the anterior insular cortex known as the frontoinsular cortex (FI) (Allman et al., 2005; Nimchinsky et al., 1999, 1995; Von Economo and Koskinas, 1925). VENs are projection neurons approximately 4.6 times the size of neighboring pyramidal neurons and are morphologically well-suited for rapid, long distance integration of information (Allman et al., 2005). The distribution of VENs is restricted to highly specific cortical regions (ACC and $\mathrm{FI}$ ), which are associated with functions including executive control of attention (Botvinick et al., 2001; Fan et al., 2003, 2005; MacDonald et al., 2000), emotional regulation (Bush et al., 2000), and both empathy and experienced pain (Singer et al., 2004). Therefore, the ACC and FI may play a role in our ability to rapidly integrate information amongst spatially distinct functional regions and make quick and intuitive judgments regarding uncertain and rapidly changing social contexts (Allman et al., 2005).

Merging perspectives from studies of the role of the ACC and FI in emotional processing with those from other cognitive domains may provide unique insight into the function of these structures. We hypothesized that the ACC and FI are involved in rapid processing of salient facial emotional information such as fear. For the purposes of our current inquiry, we designed an emotional face priming paradigm in which participants were asked to make a decision regarding the emotional valence of a target face (neutral or fearful) that was primed briefly either by a face expressing neutral or fearful affect, or by a nonface object. The prime was designed to be orthogonal to the target response, therefore did not have predictive value and could be ignored. If the prime impacts the target response, this indicates a positive or negative priming effect and implies that the prime is processed rapidly. Comparison between the non-face and face primes allows us to examine the role of these regions in rapid processing of faces, and comparison between fearful and neutral face primes is intended to examine regions involved in rapid processing of salient emotional expression. We expected fearful face primes to activate the ACC and the FI in the rapid processing of salient emotion primes.

\section{Methods}

\section{Participants}

Healthy adult volunteers ( $\mathrm{N}=25,13$ women, age range 2158 years, with mean age of 31.4 years) participated in this study. The consent procedure was approved by the institutional review board of Mount Sinai School of Medicine and written informed consent was obtained from each participant. Participants were screened for contradictions for MRI: (1) claustrophobia or anxiety of sufficient intensity to preclude being in the scanner; (2) any type of metal in the body that cannot be removed; (3) visual disturbance of sufficient severity as to impair performance while in the scanner with correction glasses; (4) history of head injury with loss of consciousness, neurological or cardiovascular disease, and traumatic brain injury or any other condition that is likely to affect brain function. All subjects were screened for Axis I psychiatric disorders using the Structured Clinical Interview for the DSM-IV (First et al., 2002).

\section{Emotional face priming task}

The emotional face priming task (see Fig. 1) uses the fearful facial expressions from a standard set of pictures of facial affect (Ekman and Friesen, 1976), which have previously been shown to robustly activate the human amygdala (Whalen et al., 2004). The information from the prime face can be processed consciously or automatically depending on the parameters of the task (Esteves and Ohman, 1993). This task is different from the backward masking task (Nomura et al., 2004; Sheline et al., 2001) in which emotional processing is subconscious, or the emotional expression/identity matching task (Hariri et al., 2000, 2002a,b; Tessitore et al., 2002) in which rapid emotional priming is not explicitly implied.

The emotional face priming task consisted of five sessions of trials (four sessions for emotion identification and a last session for face recognition). The last session of face recognition was out of the direct interest of this study and therefore will not be further reported or discussed in this paper. For the four emotion-identification sessions, participants were instructed that they would see a series of pictures with neutral or fearful expressions. Two pictures were presented, one after the other, during each trial. The first picture (a blank oval shape (B), a neutral face $(N)$, or a face exhibiting fear $(F)$ ) was the prime and the second picture (a neutral face $(\mathrm{N}$ ) or a face exhibiting fear $(\mathrm{F})$ ) was the target. The oval shape had a mean intensity (in black and white) and mean area of all the face pictures used in this task. In one third of the presentations, the first picture was a non-face oval shape and the second picture was a face with emotional expression. In another third of the presentations, the two pictures were the same faces with the same emotional expression, and in the remaining third of the presentations the two pictures were the same faces but with different emotional expressions. This created 6 prime-target combinations (BN, BF, NN, FF, FN, and NF) with equal probability. Trial order was pseudo-randomized so that each of these 6 trial types had equal chance to occur following the preceding trial type. The participants were instructed to use their right hand to press a button if the target had a neutral expression, and another button if the target had a fearful expression. For each trial, a prime picture was displayed for $200 \mathrm{~ms}$, followed by a $300 \mathrm{~ms}$ interval before the target was displayed for $1000 \mathrm{~ms}$. Participants were allowed $2500 \mathrm{~ms}$ to respond to the target. The inter-trial-interval was jittered with $2.5,2.75,3,3.75,6.5$, and $14.5 \mathrm{~s}$ discrete durations with an average of $5.5 \mathrm{~s}$. The participants saw a "+" symbol between presentations of stimuli, as a reminder to remain focused on the screen at all times. The total duration for each block was $288 \mathrm{~s}$ long. The face priming sessions each contained 36 trials with 4 models. Half of the models were male faces. Each session started and ended with a $36 \mathrm{~s}$ fixation period. The total time required to complete this task was $25 \mathrm{~min}$. Behavioral responses in terms of reaction time (RT) and accuracy were recorded.

\section{Image acquisition}

All procedures were conducted at Mount Sinai School of Medicine. Participants were scanned in a $3 \mathrm{~T}$ Siemens Allegra MR scanner, equipped with a high-performance head gradient system with maximum gradient strength of $40 \mathrm{mT} / \mathrm{m}$ and slew rate of $400 \mathrm{mT} /$ $\mathrm{m} / \mathrm{s}$. This allowed reduced susceptibility-induced distortions in single-shot echo-planar imaging (EPI) due to ultra-short echospacing. Following the informed consent process, comprehension of the task demands were ascertained with brief practice blocks of the emotional face priming task and the face recognition task, with different faces from those used in the scan session. The practice took about $10 \mathrm{~min}$. Participants were then positioned in the MRI scanner. A fast scout scan was performed to decide the localization of the slices. Then, a T2-weighted anatomical volume of the brain was acquired with a turbo spin-echo pulse sequence with repetition time $(T R)=$ $4500 \mathrm{~ms}$, echo time $(\mathrm{TE})=106 \mathrm{~ms}$, flip angle $=170^{\circ}$, field of view $(\mathrm{FOV})=210 \mathrm{~mm}$, and a matrix of $512 \times 448$. Forty-two axial slices were acquired at a thickness of $2.5 \mathrm{~mm}$ with a skip of $0.825 \mathrm{~mm}$ and an in-plane resolution of $0.41 \times 0.41 \mathrm{~mm}^{2}$. Slices were acquired along axial planes parallel to the anterior commissure-posterior commissure line. Functional $\mathrm{T} 2{ }^{*}$-weighted images depicting the blood oxygen level-dependent (BOLD) signal were then acquired at the same 42 slice locations using gradient-echo echo-planar imaging sequences with $\mathrm{TR}=3 \mathrm{~s}, \mathrm{TE}=27 \mathrm{~ms}$, flip angle $=85^{\circ}, \mathrm{FOV}=210 \mathrm{~mm}$, and acquisition matrix $=64 \times 64,2.5 \mathrm{~mm}$ thick, skip $=0.825 \mathrm{~mm}$, while the participants performed the emotional face priming task and the 

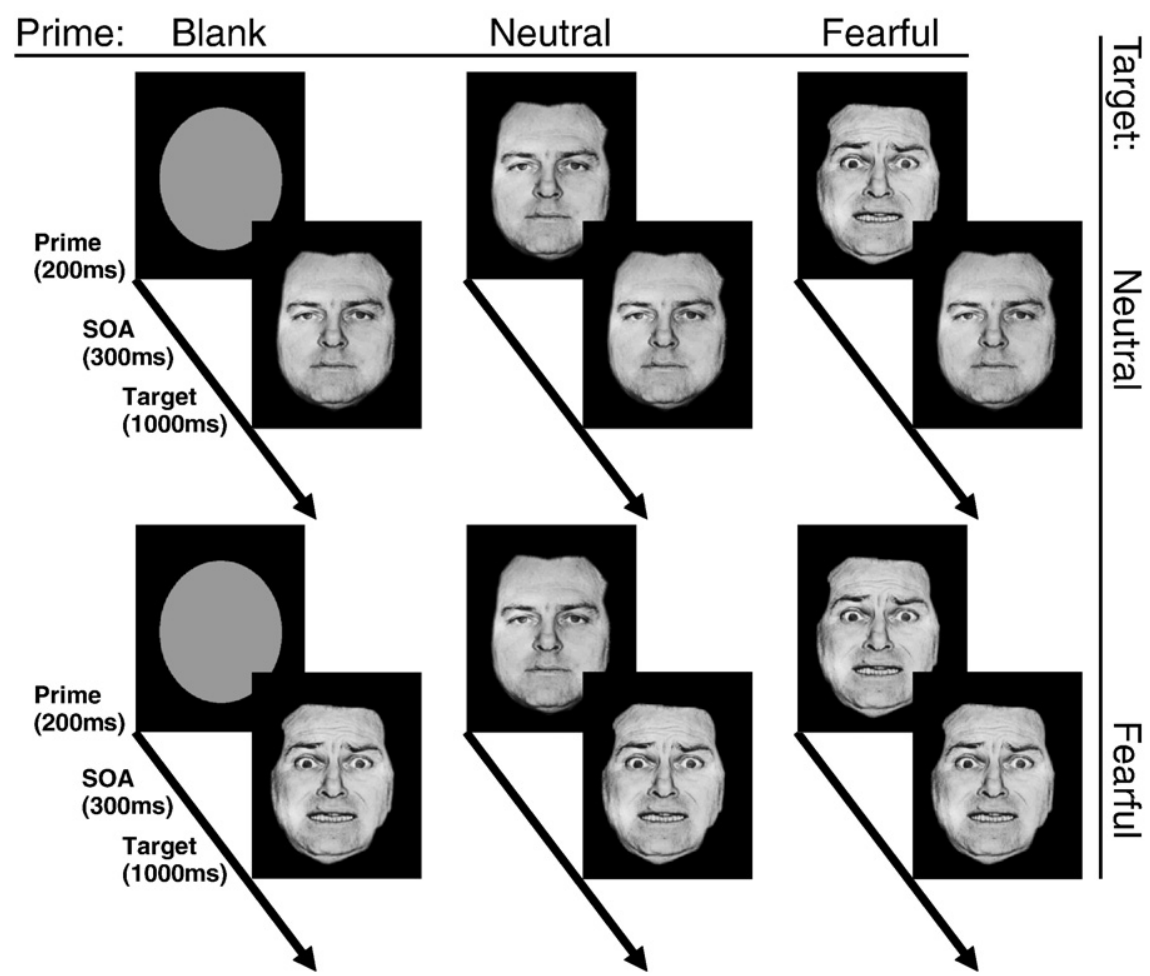

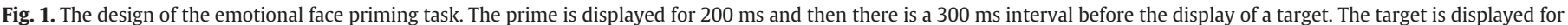

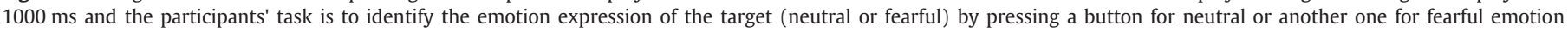

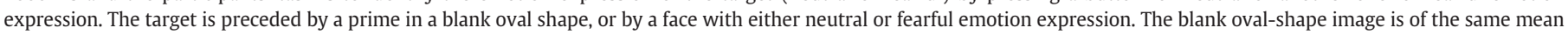
area and intensity of all face images used in this task. SOA: stimulus onset asynchrony.

face recognition task. Each EPI scan took about 5 min. The TR was a trade-off for whole-brain coverage with thinner slices that minimized distortions and increased sensitivity in regions of interest, such as the amygdala, as used in our another study (Schulz et al., 2009).

\section{Behavioral data analysis}

The primary analyses of the behavioral data from the face priming task were to compare reaction time and accuracy under the prime and target conditions and the interactions between the prime and the target conditions using a repeated-measures analysis of variance (ANOVA) with conditions of prime (fearful or neutral facial expression, and non-face oval shape) and target emotion (fearful and neutral) as the within-subjects factors. The $\alpha$ level for these analyses was set to 0.01 .

\section{fMRI data analysis}

Event-related analyses of the functional imaging data were conducted using statistical parametric mapping (SPM2; Wellcome Trust Centre for Neuroimaging, London, UK). The functional scans were realigned to the first volume (after the first two volumes were discarded), coregistered to the T2 image, normalized to a standard template (Montreal Neurological Institute), and spatially smoothed with an 8-mm full-width-at-half-maximum (FWHM) Gaussian kernel. General linear modeling then was conducted for the functional scans from each participant by modeling the observed event-related BOLD signals and regressors to identify the relationship between the experimental events and the hemodynamic response. The default SPM basis function (a synthetic hemodynamic response function), which is composed of two gamma functions (Friston et al., 1998), was used. Regressors were created by convolving a train of delta functions representing the sequence of individual trials with the SPM basis function. Five orthogonal regressors were included in a multiple regression model by convolving basis function with delta functions of: (1) prime and target pairs (500 $\mathrm{ms}$ apart) representing all prime/ target-related responses, as essentially a baseline of the combined prime and target responses; (2) face primes (prime onset locked, including both neutral and fearful faces); (3) fearful face primes (prime onset locked); (4) fearful face targets (target onset locked); and (5) fearful face targets following fearful face primes (target onset locked). The second regressor is a superset that includes all conditions in the third regressor. The fourth regressor is also a superset that includes all conditions in the fifth regressor. While these regressors are orthogonal to each other, they may still share a lot of variance. This model attempts to separate the prime- and target-related responses in a method similar to the decomposition in partial-trial design (Ollinger et al., 2001a,b; Ruge et al., 2009). The 6 parameters generated during motion correction were entered as covariates. Low-frequency drifts in signal were removed using a high-pass filter with a $128 \mathrm{~s}$ cutoff. Serial correlation was estimated using an autoregressive AR(1) model.

The specific brain responses were tested by applying appropriate linear contrasts (in this case, each regressor was contrasted to baseline rather than a control condition regressor) to the parameter estimates, resulting in contrast maps for each participant. The contrast images of all participants were entered into a second-level randomeffects group analysis. The resultant voxel-wise statistical maps were thresholded for significance using a $\mathrm{p}<0.01$ for the height threshold of each voxel and a $\mathrm{p}<0.05$ for the extent threshold. In addition, a Monte Carlo simulation of the brain volume of the current study was also conducted to confirm that the above voxel contiguity threshold is appropriate. Assuming an individual voxel type I error of $\mathrm{p}<0.01$, a cluster extent of 85 contiguous resampled voxels $\left(2 \times 2 \times 2 \mathrm{~mm}^{3}\right)$ was indicated as necessary to correct for multiple voxel comparisons at $\mathrm{p}<0.01$. For the simulation, $8 \mathrm{~mm}$ FWHM smooth parameter was used in addition to the image resolution parameters. For a description of this method, see a previous publication (Slotnick and Schacter, 2004). 

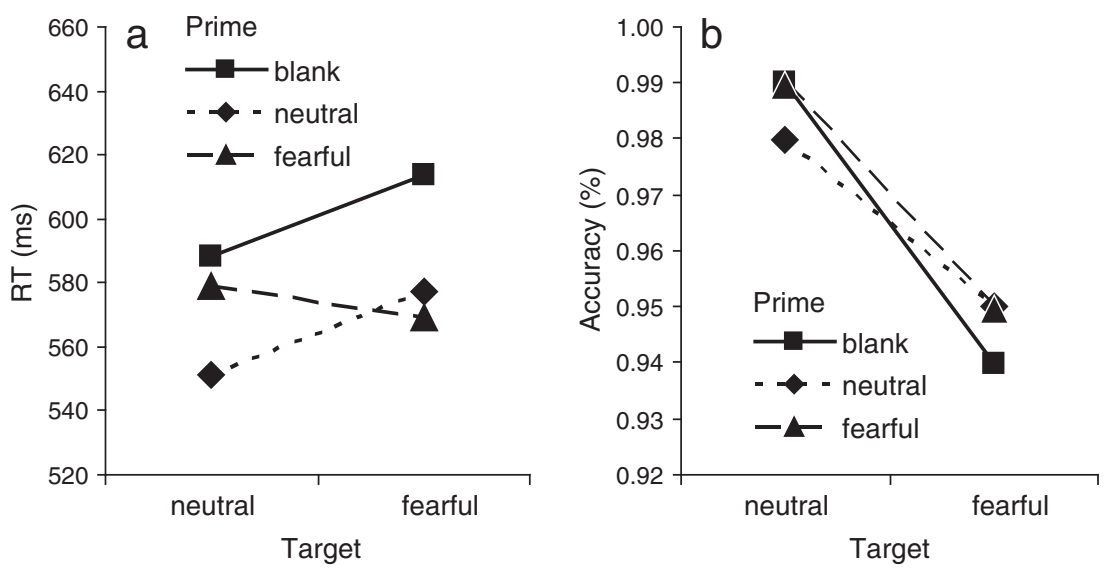

Fig. 2. Behavioral results for the 6 conditions of 3 priming categories (blank, neutral, and fearful) by 2 target categories (neutral and fearful). (a) Reaction time. (b) Accuracy.

The voxel number of the extent threshold decided by SPM was greater than 85. Therefore, the resultant statistical maps thresholded for height and extent protect against an inflation of the false-positive rate. The presumed locations of the real effects reported in the tables (i.e., the $\mathrm{x}, \mathrm{y}$, and $\mathrm{z}$ coordinates) could be off by a fair distance due to the low uncorrected threshold and large spatial extent. Amygdala activation was thresholded with $\mathrm{p}<0.05$ using small volume correction (Worsley et al., 1996), with an anatomical mask derived from the anatomical automatic labeling atlas (Tzourio-Mazoyer et al., 2002).

\section{Results}

\section{Behavioral responses}

Fig. 2 shows the behavioral results in terms of RT and accuracy. A 3 (prime: blank, neutral, and fearful) $\times 2$ (target: neutral and fearful) repeated-measures ANOVA was carried out using the median RTs of subject as the dependent variable to minimize the influence of trials with outlier RTs. There was a significant main effect of prime $\left(\mathrm{F}_{(2,48)}=17.85, \mathrm{p}<0.001\right)$. The main effect of target was not significant $\left(\mathrm{F}_{(1,24)}=1.48, \mathrm{p}>0.05\right)$. There was a significant prime by target interaction $\left(\mathrm{F}_{(2,48)}=4.90, \mathrm{p}=0.01\right)$. Planned simple comparisons showed that target responses following a face prime were faster than following a blank prime $\left(\mathrm{F}_{(1,24)}=32.85, \mathrm{p}<0.001\right)$, reflecting a facilitation effect of face prime on performance. The differences between neutral and fearful primes, and between neutral and fearful targets were not significant $\left(F_{(1,24)}=2.43\right.$ and $F_{(1,24)}=1.48$, both $\mathrm{p}>0.05$ ). However, the face prime (neutral, fearful) by target (neutral, fearful) interaction was significant $\left(F_{(1,24)}=6.44\right.$, $\mathrm{p}=0.02$ ). Thus, although RTs to fearful face targets were generally increased relative to those to neutral face targets in the context of blank and neutral face primes, RTs to fearful targets were decreased in the context of emotionally congruent fearful primes, a facilitation effect. The same analysis was also conducted using error rates as the dependent variable. A main effect of target was found $\left(F_{(1,24)}=8.53\right.$, $\mathrm{p}<0.01$ ) such that subjects identified neutral face targets more accurately than fearful face targets. The main effect of prime was not significant $(\mathrm{F}<1)$ and the prime by target interaction was not significant $(\mathrm{F}<1)$.

\section{The functional activation of the brain}

Fig. 3 shows the pattern of activation related to (a) all primes and targets, (b) face primes, (c) fearful primes, (d) fearful targets, and (e) fearful prime and fearful target combination. Tables 1-5 list the activation associated with the above five regressors.
For the prime- and target-related responses (Fig. 3a and Table 1), there was involvement of the frontoparietal network including the posterior rostral cingulate zone (RCZp) and caudal cingulate zone (CCZ) (see Fan et al. (2008) for the functional separation of these subregions), supplementary motor area (SMA), frontal eye fields, the area near and along the intraparietal sulcus, and the fusiform gyrus. Bilateral FI was also activated, indicating its involvement in general information processing of the prime and the target.

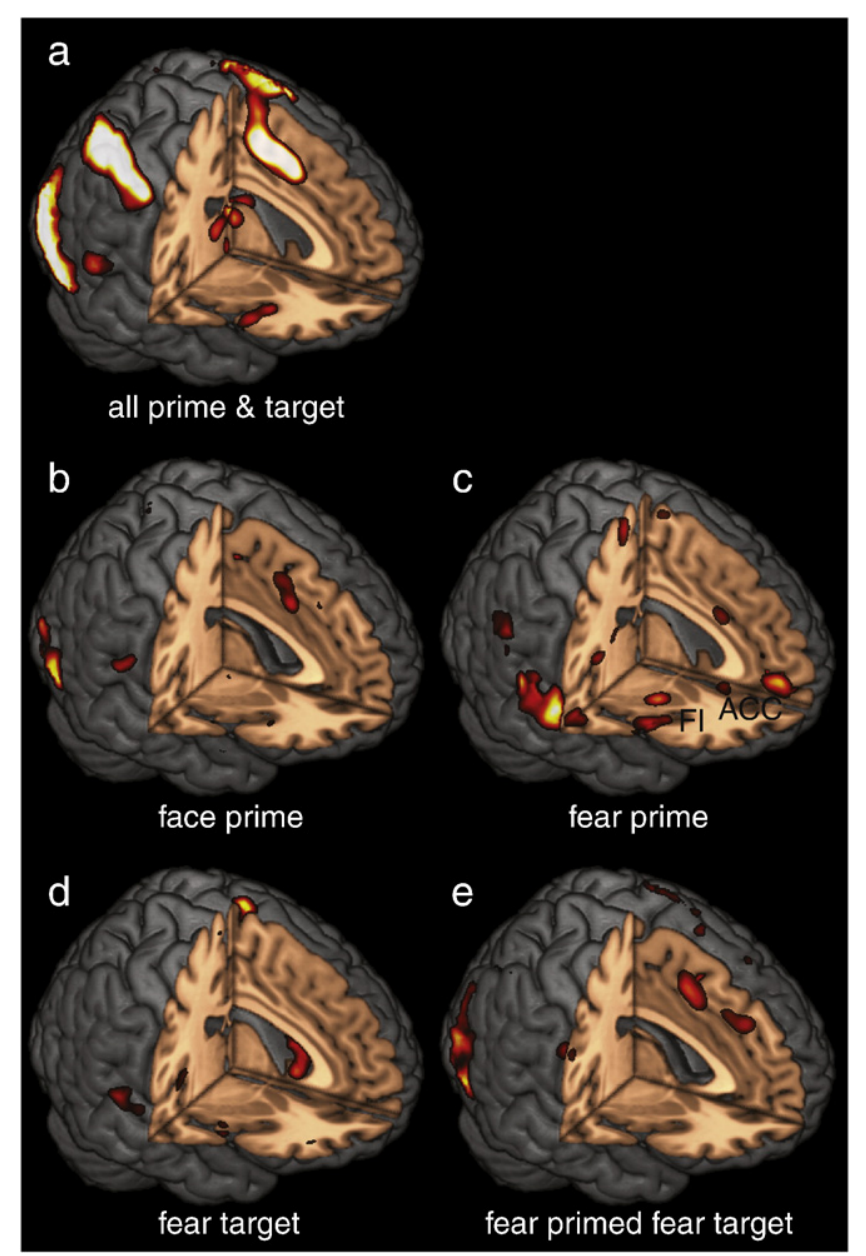

Fig. 3. Brain activation related to the regressors of (a) all prime and target events in common, (b) face prime, (c) fearful face prime specific, (d) fearful target, and (e) fearful face target following fearful face prime. ACC: anterior cingulate cortex; FI: Frontoinsular cortex. Color heat is mapped for a range of 2.5 to 5 of $t$ value. 
Table 1

Functional activation associated with all prime (blank, neutral, and fearful) and target (neutral and fearful faces) events in common.

\begin{tabular}{|c|c|c|c|c|c|c|c|c|}
\hline Region & $\mathrm{L} / \mathrm{R}$ & $\mathrm{BA}$ & $\mathrm{x}$ & $\mathrm{y}$ & $\mathrm{z}$ & $t$ & Z & Voxel \\
\hline Cerebellum $^{\mathrm{a}}$ & $\mathrm{L}$ & 37 & -32 & -56 & -24 & 15.29 & 7.48 & 22,505 \\
\hline Lingual gyrus & $\mathrm{R}$ & 17 & 6 & -82 & -10 & 13.33 & 7.09 & \\
\hline Cerebellum & $\mathrm{R}$ & 37 & 34 & -48 & -24 & 13.19 & 7.06 & \\
\hline Postcentral gyrus & $\mathrm{L}$ & 2 & -44 & -36 & 48 & 13.91 & 7.21 & 7367 \\
\hline Inferior parietal lobule ${ }^{\mathrm{b}}$ & $\mathrm{L}$ & 40 & -32 & -42 & 42 & 9.99 & 6.22 & \\
\hline Supplementary motor area & $\mathrm{L}$ & & -4 & 2 & 50 & 8.77 & 5.82 & \\
\hline Precentral gyrus & $\mathrm{R}$ & 4 & 42 & 8 & 30 & 11.44 & 6.63 & 1887 \\
\hline Precentral gyrus & $\mathrm{R}$ & 6 & 36 & 2 & 48 & 6.31 & 4.80 & \\
\hline Middle frontal gyrus & $\mathrm{R}$ & 6 & 34 & 2 & 62 & 5.67 & 4.48 & \\
\hline Posterior cingulate gyrus & $\mathrm{L}$ & 23 & 2 & -28 & 28 & 7.61 & 5.38 & 244 \\
\hline Thalamus & $\mathrm{L}$ & & -12 & -16 & 8 & 5.48 & 4.37 & 330 \\
\hline Thalamus & $\mathrm{R}$ & & 10 & -14 & 10 & 3.82 & 3.35 & \\
\hline Rolandic operculum & $\mathrm{L}$ & & -38 & -4 & 16 & 5.42 & 4.34 & 182 \\
\hline Insula & $\mathrm{L}$ & & -44 & 0 & 6 & 4.25 & 3.64 & \\
\hline Insula & $\mathrm{L}$ & & -34 & 20 & 6 & 3.85 & 3.36 & \\
\hline Thalamus & $\mathrm{L}$ & & -14 & -30 & -2 & 5.28 & 4.26 & 217 \\
\hline Thalamus & $\mathrm{L}$ & & -8 & -22 & -10 & 3.47 & 3.09 & \\
\hline Insula & $\mathrm{R}$ & & 32 & 24 & 2 & 4.50 & 3.79 & 340 \\
\hline
\end{tabular}

Note: ${ }^{\text {TThis }}$ cluster also includes left and right fusiform gyrus. ${ }^{\mathrm{D}}$ Intraparietal gyrus. The ordering of these regions is based on the $t$ value.

For the response to face primes (Fig. $3 \mathrm{~b}$ and Table 2), in addition to visual areas including bilateral fusiform gyrus, inferior occipital gyrus, and other regions, RCZp and SMA activation persisted above and beyond the common response to all primes and targets. The FI activation was not significantly increased. Importantly, however, for fearful face priming (Fig. $3 \mathrm{c}$ and Table 3), clusters of significant activation were found in pregenual ACC, the FI, and the middle temporal gyrus bilaterally, among other regions. Right amygdala response to fearful primes was also significant (see the note of Table 3).

For the fearful-target specific response (Fig. 3d and Table 4), several regions, such as left precentral gyrus, bilateral superior temporal gyrus, right anterior insula adjacent to mid-insula, and left caudate were activated. For the response to fearful targets following fearful primes (Fig. 3e and Table 5), right RCZp and medial portion of the superior frontal gyrus, along with the precentral gyrus, showed increased activation.

\section{Discussion}

Our face priming task was designed such that primes did not predict targets in any way. Because of this orthogonal design, any response to the primes suggests rapid processing of information. We

Table 2

Functional activation associated with all face (neutral and fearful) primes.

\begin{tabular}{llrllllll}
\hline Region & $\mathrm{L} / \mathrm{R}$ & $\mathrm{BA}$ & $\mathrm{x}$ & $\mathrm{y}$ & $\mathrm{z}$ & $t$ & $\mathrm{Z}$ & Voxel \\
\hline Lingual gyrus & $\mathrm{L}$ & 18 & -16 & -88 & -14 & 6.00 & 4.64 & 1557 \\
$\quad$ Inferior occipital gyrus & $\mathrm{L}$ & 19 & -38 & -86 & -8 & 5.95 & 4.62 & \\
Inferior occipital gyrus & $\mathrm{L}$ & 18 & -26 & -92 & -4 & 4.95 & 4.07 & \\
Middle frontal gyrus & $\mathrm{R}$ & 6 & 42 & 0 & 56 & 5.08 & 4.15 & 1173 \\
$\quad$ Inferior frontal gyrus & $\mathrm{R}$ & 44 & 50 & 18 & 22 & 4.93 & 4.06 & \\
Inferior frontal gyrus & $\mathrm{R}$ & 44 & 42 & 2 & 26 & 4.39 & 3.72 & \\
Fusiform gyrus & $\mathrm{R}$ & 37 & 34 & -60 & -12 & 5.01 & 4.11 & 1529 \\
Inferior occipital gyrus & $\mathrm{R}$ & 19 & 46 & -76 & -8 & 4.95 & 4.07 & \\
Lingual gyrus & $\mathrm{R}$ & 19 & 22 & -56 & -4 & 4.79 & 3.97 & \\
Calcarine cortex & $\mathrm{L}$ & 17 & -16 & -70 & 8 & 4.13 & 3.55 & 223 \\
$\quad$ Lingual gyrus & $\mathrm{L}$ & 17 & -12 & -64 & 4 & 3.68 & 3.25 & \\
Anterior cingulate gyrus & $\mathrm{R}$ & 24 & 4 & 20 & 38 & 3.62 & 3.20 & 173 \\
Supplementary motor area & $\mathrm{R}$ & 32 & 4 & 16 & 48 & 3.10 & 2.82 & \\
Anterior cingulate gyrus & $\mathrm{L}$ & 24 & -8 & 8 & 38 & 2.73 & 2.52 & \\
Precentral gyrus & $\mathrm{L}$ & 4 & -30 & -28 & 60 & 3.47 & 3.09 & 181 \\
Precentral gyrus & $\mathrm{L}$ & 4 & -32 & -26 & 52 & 3.26 & 2.94 & \\
Precentral gyrus & $\mathrm{L}$ & 6 & -34 & -14 & 64 & 3.10 & 2.81 & \\
\hline
\end{tabular}

Table 3

Functional activation specifically associated with fearful face prime.

\begin{tabular}{|c|c|c|c|c|c|c|c|c|}
\hline Region & $\mathrm{L} / \mathrm{R}$ & $\mathrm{BA}$ & $\mathrm{x}$ & $\mathrm{y}$ & $\mathrm{z}$ & $t$ & Z & Voxel \\
\hline Superior temporal gyrus ${ }^{\mathrm{a}}$ & $\mathrm{L}$ & 38 & -54 & 6 & -10 & 5.54 & 4.40 & 1218 \\
\hline Superior temporal gyrus & $\mathrm{L}$ & 22 & -64 & -14 & -6 & 5.10 & 4.16 & \\
\hline Superior temporal gyrus & $\mathrm{L}$ & 22 & -54 & -42 & 2 & 4.18 & 3.59 & \\
\hline $\begin{array}{l}\text { Medial frontal gyrus/ } \\
\text { pregenual ACC }\end{array}$ & $\mathrm{L}$ & $10 / 32$ & -12 & 54 & -2 & 5.47 & 4.36 & 348 \\
\hline Superior frontal gyrus & $\mathrm{L}$ & 10 & -20 & 54 & 6 & 2.89 & 2.65 & \\
\hline Pregenual ACC & $\mathrm{L}$ & 32 & -16 & 36 & 10 & 2.67 & 2.47 & \\
\hline Superior temporal gyrus & $\mathrm{R}$ & 21 & 62 & -22 & 0 & 5.09 & 4.15 & 730 \\
\hline Superior temporal gyrus & $\mathrm{R}$ & 22 & 66 & -38 & 12 & 4.57 & 3.84 & \\
\hline Superior temporal gyrus & $\mathrm{R}$ & 22 & 52 & -36 & 6 & 4.32 & 3.68 & \\
\hline Insula & $\mathrm{R}$ & & 44 & 16 & -2 & 4.81 & 3.99 & 219 \\
\hline Insula & $\mathrm{R}$ & & 36 & 20 & -6 & 3.15 & 2.86 & \\
\hline Insula & $\mathrm{R}$ & & 46 & 8 & 2 & 3.00 & 2.74 & \\
\hline Middle temporal gyrus & $\mathrm{L}$ & 37 & -56 & -58 & 18 & 4.63 & 3.88 & 230 \\
\hline Superior temporal gyrus & $\mathrm{R}$ & 39 & 48 & -52 & 24 & 4.26 & 3.64 & 161 \\
\hline Angular gyrus & $\mathrm{R}$ & 39 & 58 & -56 & 30 & 2.77 & 2.56 & \\
\hline Supramarginal gyrus & $\mathrm{R}$ & & 50 & -38 & 26 & 2.77 & 2.55 & \\
\hline Caudate & & & 22 & -10 & 20 & 3.79 & 3.32 & 214 \\
\hline Heschl gyrus & $\mathrm{R}$ & & 38 & -26 & 16 & 3.49 & 3.11 & \\
\hline Insula & $\mathrm{R}$ & & 36 & -14 & 16 & 3.45 & 3.08 & \\
\hline Suppementary motor area & $\mathrm{R}$ & 6 & 12 & -14 & 70 & 3.69 & 3.25 & 148 \\
\hline Suppementary motor area & $\mathrm{L}$ & 6 & -2 & -6 & 70 & 3.06 & 2.79 & \\
\hline Superior frontal gyrus & $\mathrm{R}$ & 6 & 22 & -12 & 70 & 2.81 & 2.59 & \\
\hline Cuneus & $\mathrm{L}$ & 23 & -14 & -62 & 24 & 3.37 & 3.02 & 175 \\
\hline Precuneus & $\mathrm{L}$ & & 0 & -60 & 30 & 3.01 & 2.75 & \\
\hline Precuneus & $\mathrm{L}$ & & -12 & -58 & 32 & 2.84 & 2.61 & \\
\hline
\end{tabular}

Note: ${ }^{\text {T}}$ The cluster also extends to the left insula $(x=-34, y=18, z=-10)$. For the right amygdala, peak $\mathrm{x}=22, \mathrm{y}=2, \mathrm{z}=-20, t=2.43, \mathrm{Z}=2.28, \mathrm{p}_{\text {uncorrected }}=0.01$, $\mathrm{k}=49$ voxels, with a voxel-level threshold $\mathrm{p}_{\text {uncorrected }}<0.05$ and a search volume of $1872 \mathrm{~mm}^{3}$ (234 voxels). The right putamen activation $(\mathrm{x}=22, \mathrm{y}=8, \mathrm{z}=-6, t=4.05$, $\mathrm{Z}=3.50$, and $\mathrm{k}=83)$, the sub-genual ACC $(\mathrm{x}=4, \mathrm{y}=40, \mathrm{z}=2, t=3.09, \mathrm{Z}=2.81$, and $\mathrm{k}=100)$, and the anterior rostral cingulate zone $(\mathrm{x}=-4, \mathrm{y}=24, \mathrm{z}=28, t=3.19$, $\mathrm{Z}=2.88$, and $\mathrm{k}=52$ ) shown in Fig. $3 \mathrm{c}$ did not pass the extent threshold. Therefore, they were not listed in this table.

found faster RTs in trials primed by face primes relative to those primed by non-face primes, accompanied by enhanced activation in regions such as the fusiform gyrus, RCZp of the ACC and SMA, but not the FI. Most importantly, the pregenual ACC and FI were highly activated by fearful primes, suggesting that these regions that contain VENs are involved in rapid processing of salient emotional information, thus supporting our hypothesis that the ACC and FI are involved in rapid emotional information processing. We also found that the pregenual ACC and FI were coactivated with the amygdala in response to fearful primes relative to neutral face primes, suggesting that the ACC and FI, together with the amygdala, subserve the rapid detection and assessment of threatening stimuli. Furthermore, RTs in emotional categorization of fearful faces were increased relative to neutral faces, which is consistent with a previous report (Calvo and Lundqvist, 2008). Accuracy was decreased for fearful targets relative to neutral targets, which was associated with increased activation in the right anterior insula extending to middle insula, left caudate, and left precentral gyrus. There was also a prime by target interaction such that fearful primes facilitated the processing of fearful targets. This

Table 4

Functional activation associated with fearful face target.

\begin{tabular}{llrrrrrrl}
\hline Region & $\mathrm{L} / \mathrm{R}$ & $\mathrm{BA}$ & $\mathrm{x}$ & $\mathrm{y}$ & $\mathrm{z}$ & \multicolumn{1}{l}{$t$} & $\mathrm{Z}$ & Voxel \\
\hline Parahippocampal gyrus & $\mathrm{L}$ & 27 & -6 & -38 & 8 & 5.14 & 4.18 & 283 \\
Precentral gyrus & $\mathrm{L}$ & 6 & -20 & -18 & 70 & 4.90 & 4.04 & 192 \\
Superior temporal gyrus & $\mathrm{L}$ & 22 & -60 & -30 & 14 & 4.61 & 3.86 & 143 \\
Insula $^{\mathrm{a}}$ & $\mathrm{R}$ & & 46 & -6 & 8 & 4.08 & 3.52 & 295 \\
$\quad$ Insula & $\mathrm{R}$ & & 44 & 4 & 2 & 3.22 & 2.91 & \\
$\quad$ Superior temporal gyrus & $\mathrm{R}$ & 22 & 58 & 0 & 6 & 3.09 & 2.81 & \\
Caudate & $\mathrm{L}$ & & -8 & 16 & 2 & 3.85 & 3.36 & 152 \\
$\quad$ Caudate & $\mathrm{L}$ & & -10 & 14 & 12 & 3.59 & 3.18 & \\
\hline
\end{tabular}

Note: anterior insula but adjacent to mid insula according to references (Mutschler et al., 2009; Naidich et al., 2004). 
Table 5

Functional activation associated with fearful face targets primed by fearful face primes.

\begin{tabular}{lllrrrrrr}
\hline Region & $\mathrm{L} / \mathrm{R}$ & $\mathrm{BA}$ & $\mathrm{x}$ & $\mathrm{y}$ & $\mathrm{z}$ & $t$ & $\mathrm{Z}$ & Voxel \\
\hline Cerebellum & $\mathrm{L}$ & & -20 & -48 & -26 & 5.32 & 4.28 & 4331 \\
$\quad$ Cerebellum & $\mathrm{L}$ & & -32 & -42 & -24 & 5.05 & 4.13 & \\
$\quad$ Inferior occipital gyrus & $\mathrm{R}$ & 19 & 42 & -80 & -10 & 4.65 & 3.89 & \\
Precentral gyrus & $\mathrm{L}$ & 6 & -42 & 2 & 30 & 5.06 & 4.13 & 374 \\
Precentral gyrus & $\mathrm{R}$ & 6 & 42 & 4 & 26 & 4.39 & 3.73 & 784 \\
$\quad$ Inferior frontal gyrus & $\mathrm{R}$ & 44 & 40 & 18 & 20 & 4.28 & 3.65 & \\
$\quad$ Inferior frontal gyrus & $\mathrm{R}$ & 44 & 38 & 12 & 38 & 3.45 & 3.08 & \\
Precentral gyrus & $\mathrm{L}$ & 4 & -36 & -18 & 62 & 4.28 & 3.65 & 459 \\
$\quad$ Postcentral gyrus & $\mathrm{L}$ & 3 & -38 & -28 & 52 & 3.64 & 3.21 & \\
Postcentral gyrus & $\mathrm{L}$ & 3 & -30 & -26 & 54 & 3.51 & 3.12 & \\
Anterior cingulate gyrus & $\mathrm{R}$ & 32 & 8 & 14 & 46 & 3.93 & 3.42 & 529 \\
$\quad$ Medial superior & $\mathrm{L}$ & $9 / 32$ & 2 & 40 & 36 & 3.27 & 2.95 & \\
frontal gyrus & & & & & & & & \\
$\quad$ Medial superior & $\mathrm{L}$ & $8 / 32$ & 2 & 32 & 40 & 2.91 & 2.66 & \\
frontal gyrus & & & & & & & & \\
\hline
\end{tabular}

Note: For left amygdala, peak $\mathrm{x}=-20, \mathrm{y}=-2, \mathrm{z}=-22, t=2.97, \mathrm{Z}=2.72$, $\mathrm{p}_{\text {uncorrected }}=0.003, \mathrm{k}=128$ voxels, with a voxel-level threshold $\mathrm{p}_{\text {uncorrected }}<0.05$ and a search volume of $1728 \mathrm{~mm}^{3}$ (216 voxels).

facilitation effect, namely, a shorter RT for the fear-primed fearful targets (compared to the trend of the blank and neutral primed fearful targets), was accompanied by greater activation in the RCZp of the ACC.

We observed activation by fearful primes, in addition to face primes, in different subdivisions of the ACC. However, only responses to fearful primes (except a general response to all primes and targets) induced significant activation of the FI. The additive activation of the RCZp for face primes may represent additional information processing of general facial information compared to blank primes. The pregenual ACC is a subdivision of the cingulate cortex that subserves emotional processing (Bush et al., 2000). Activation of the pregenual ACC, together with that of the FI for fearful primes may be responsible for emotional regulation and linked to amygdala activity. A similar, although non-significant, pattern of results was obtained in a cortical source analysis of ERP data collected during a fearful/happy priming task using only surprise faces as targets, with increased current source density for fearful faces in the pregenual ACC and FI (Li et al., 2008). The pre- and sub-genual ACC regions have been implicated in responses to socially significant or provocative information and that abnormally decreased activation in this region has been linked to mood disorders (Drevets et al., 1997).

The right insula activation by fearful targets compared to neutral targets may be attributed to autonomic responses to fearful stimuli or to the negative affect associated with poor behavioral performance (lower accuracy and the trend of longer RT). The functionality of the subregions of the insular cortex needs to be further investigated. We may follow the methods as in a recent meta-analysis (Mutschler et al., 2009) to investigate the functional roles of the subregions of the insula under the context of emotional information processing. For example, whereas insular activation by the fearful targets is located at the dorsal-posterior part of the anterior insular cortex (AIC), activation caused by the fearful primes is located at the ventral AIC which has been shown to be related to physiological change (Mutschler et al., 2009). Given that the amygdala is reciprocally connected with the insular cortex (Hoistad and Barbas, 2008), the insular cortex is usually coactivated with the amygdala, as shown in a meta-analysis (Kober et al., 2008).

The rostral and dorsal regions of the ACC have been implicated in both the acquisition phase and the conditioned response in classical conditioning paradigms (Milad et al., 2007; Phelps et al., 2004), and activity in a homologous region of the ACC having dense connections with the amygdala has been shown to modulate associative learning during fear conditioning (Bissiere et al., 2008). The role of the insula in regulation of emotion has been linked to the awareness of conditioned and unconditioned stimulus contingencies (Phelps et al., 2001). The medial prefrontal cortex, which includes the orbito- frontal cortex, ACC (area 25, i.e., the subcallosal gyrus, and area 32), and anterior prefrontal cortex (PFC; area 9), has also been implicated in emotional processing (Devinsky et al., 1995; Price and Amaral, 1981; Vogt et al., 1992). The basolateral amygdala has dense connections with the ventromedial PFC (vmPFC) (Amaral and Price, 1984), and animal studies have shown that lesions of the vmPFC produce a failure to inhibit amygdala function (Morgan and LeDoux, 1995; Morgan et al., 1993). Furthermore, an amygdala-prefrontal functional connectivity study showed a positive covariance of the hemodynamic responses of these two regions to emotional faces (Heinz et al., 2005).

The ACC and FI have been found to coactivate in many functional neuroimaging studies involving manipulations of information processing, such as cognitive tasks of conflict processing and decisionmaking (Nee et al., 2007; Rao et al., 2008; Sanfey, 2007), and in emotional tasks with high cognitive demand (Phan et al., 2002). The FI is regarded as the limbic sensory cortex associated with visceral sensation, whereas the ACC is viewed as the limbic motor cortex associated with autonomic and emotional control (Craig, 2002) and serves as the instrument for voluntary control (Craig, 2003). Both the ACC and FI are strongly interconnected with the amygdala (Craig, 2002). A common role of the FI in feelings, empathy, uncertainty, and awareness has been proposed recently (Craig, 2009; Singer et al., 2009). Under conditions of emotional arousal or conscious access to feelings (e.g., priming by fearful faces), there is an increase in the saliency of emotions and requirement for rapid information processing, thereby resulting in the involvement of the ACC-FI network.

The functional dissociation between the ACC/FI and other regions and networks in emotional information processing still needs to be investigated. The pregenual ACC and the FI are responsive to fearful emotional priming, suggesting that they may be the key structures for rapid processing of salient emotional stimuli. However, the ACC may be involved in top-down cognitive control while the FI may be involved in more automatic processing as suggested by a study on functional dissociation of the two regions (Gu et al., 2010). In addition, we found that the coactivation of the pregenual ACC, the FI, the amygdala, and some other regions is associated specifically with the response to fearful face primes, whereas the overall activation of the frontoparietal network is related to all types of responses. It has been proposed that the dorsal ACC and FI are involved in processing salient information, in contrast to the dorsolateral frontal and parietal cortices that represent an executive control network (Seeley et al., 2007).

The amygdala has been shown to be essential in emotional processing and modulated by emotion regulation in several functional magnetic resonance imaging (fMRI) paradigms adapted from behavioral or physiological studies including: instructed fear (Phelps et al., 2001), fear conditioning (Phelps et al., 2004), emotional Stroop (Bremner et al., 2004; Compton et al., 2003; Williams et al., 1996), threat-related distracters (Bishop et al., 2004a,b; Vuilleumier et al., 2001), face-place object selection (Anderson et al., 2003), wordemotion conflict (Etkin et al., 2006), and cognitive reappraisal (Jackson et al., 2000). Based on these studies, it has been suggested that the left amygdala activity reflects awareness of the aversive nature of the stimulus, whereas the right amygdala response is related to unconscious processing of facial emotions (Morris et al., 1998; Pegna et al., 2005). It has also been shown that the amygdala response is independent from whether the aversive stimulus is presented at attended or unattended locations (Vuilleumier et al., 2001), and that highly anxious individuals tend to have elevated amygdala responses to these stimuli and corresponding decreases in activation of structures implicated in emotional regulation, such as the lateral prefrontal cortex and the ACC (Bishop et al., 2004a,b). The finding that amygdala activation does not change when aversive stimuli are presented at attended versus unattended locations (Vuilleumier et al., 2001), and that varying the attention dedicated to the aversive 
stimulus does not affect amygdala activity (Anderson et al., 2003), suggests that the amygdala is involved in automatic or pre-attentive processing of affectively charged stimuli. In this study, although the prime could be ignored because it did not have any predictive value, it still interacted with the target response at both behavioral and neural levels. The prime face was presented $500 \mathrm{~ms}$ earlier than the target face so that the automatic processing of the prime was unavoidable.

In summary, using an emotional face priming task in which we manipulated the emotional valence of the prime and target, we observed reliable involvement of the ACC and FI in response to fearful primes compared to neutral face primes, supporting an argument of functional specificity of these regions in rapid processing of salient emotional information, which might be related to the existence and the function of the VENs in these regions. We also demonstrated that the behavioral effects are associated with these neural substrates for processing salient facial emotional information. Although we have demonstrated the involvement of the ACC and FI, we only used fearful faces compared to neutral faces to examine the saliency effect, which presents as a limitation of this study.

\section{Acknowledgments}

The study described was supported by National Center for Research Resources Grant M01RR00071. Its contents are solely the responsibility of the authors and do not necessarily represent the official views of NCRR or NIH. This work was also supported in part by a Young Investigator Award from the NARSAD and by an NIMH grant MH083164 to JF and by the James S. McDonnell Foundation (22002078) to PRH. The funders had no role in study design, data collection and analysis, decision to publish, or preparation of the manuscript. We thank Jack M. Gorman, MD, Sanjay J. Mathew, MD, Kurt P. Schulz, PhD, and Jeffrey M. Halperin, PhD, for their assistance.

\section{References}

Adolphs, R., Tranel, D., Hamann, S., Young, A.W., Calder, A.J., Phelps, E.A., Anderson, A. Lee, G.P., Damasio, A.R., 1999. Recognition of facial emotion in nine individuals with bilateral amygdala damage. Neuropsychologia 37, 1111-1117.

Allman, J.M., Watson, K.K., Tetreault, N.A., Hakeem, A.Y., 2005. Intuition and autism: possible role for Von Economo neurons. Trends Cogn. Sci. 9, 367-373.

Amaral, D.G., Price, J.L., 1984. Amygdalo-cortical projections in the monkey (Macaca fascicularis). J. Comp. Neurol. 230, 465-496.

Anderson, A.K., Christoff, K., Panitz, D., De Rosa, E., Gabrieli, J.D., 2003. Neural correlates of the automatic processing of threat facial signals. J. Neurosci. 23, 5627-5633.

Augustine, J.R., 1985. The insular lobe in primates including humans. Neurol. Res. 7, 2-10.

Berthier, M., Starkstein, S., Leiguarda, R., 1988. Asymbolia for pain: a sensory-limbic disconnection syndrome. Ann. Neurol. 24, 41-49.

Bishop, S., Duncan, J., Brett, M., Lawrence, A.D., 2004a. Prefrontal cortical function and anxiety: controlling attention to threat-related stimuli. Nat. Neurosci. 7, 184-188.

Bishop, S.J., Duncan, J., Lawrence, A.D., 2004b. State anxiety modulation of the amygdala response to unattended threat-related stimuli. J. Neurosci. 24, 10364-10368.

Bissiere, S., Plachta, N., Hoyer, D., McAllister, K.H., Olpe, H.R., Grace, A.A., Cryan, J.F., 2008. The rostral anterior cingulate cortex modulates the efficiency of amygdaladependent fear learning. Biol. Psychiatry 63, 821-831.

Botvinick, M.M., Braver, T.S., Barch, D.M., Carter, C.S., Cohen, J.D., 2001. Conflict monitoring and cognitive control. Psychol. Rev. 108, 624-652.

Bremner, J.D., Vermetten, E., Vythilingam, M., Afzal, N., Schmahl, C., Elzinga, B., Charney, D.S., 2004. Neural correlates of the classic color and emotional stroop in women with abuse-related posttraumatic stress disorder. Biol. Psychiatry 55, 612-620.

Bush, G., Luu, P., Posner, M.I., 2000. Cognitive and emotional influences in anterior cingulate cortex. Trends Cogn. Sci. 4, 215-222.

Butti, C., Sherwood, C.C., Hakeem, A.Y., Allman, J.M., Hof, P.R., 2009. Total number and volume of Von Economo neurons in the cerebral cortex of cetaceans. J. Comp. Neurol. 515, 243-259.

Calvo, M.G., Lundqvist, D., 2008. Facial expressions of emotion (KDEF): identification under different display-duration conditions. Behav. Res. Methods 40, 109-115.

Carr, L., Iacoboni, M., Dubeau, M.C., Mazziotta, J.C., Lenzi, G.L., 2003. Neural mechanisms of empathy in humans: a relay from neural systems for imitation to limbic areas. Proc. Natl Acad. Sci. USA 100, 5497-5502.

Carter, C.S., Braver, T.S., Barch, D.M., Botvinick, M.M., Noll, D., Cohen, J.D., 1998. Anterior cingulate cortex, error detection, and the online monitoring of performance. Science 280, 747-749.

Compton, R.J., Banich, M.T., Mohanty, A., Milham, M.P., Herrington, J., Miller, G.A., Scalf P.E., Webb, A., Heller, W., 2003. Paying attention to emotion: an fMRI investigation of cognitive and emotional stroop tasks. Cogn. Affect. Behav. Neurosci. 3, 81-96.
Craig, A.D., 2002. How do you feel? Interoception: the sense of the physiological condition of the body. Nat. Rev. Neurosci. 3, 655-666.

Craig, A.D., 2003. A new view of pain as a homeostatic emotion. Trends Neurosci. 26, 303-307

Craig, A.D., 2009. How do you feel - now? The anterior insula and human awareness. Nat. Rev. Neurosci. 10, 59-70.

Critchley, H.D., Wiens, S., Rotshtein, P., Ohman, A., Dolan, R.J., 2004. Neural systems supporting interoceptive awareness. Nat. Neurosci. 7, 189-195.

Devinsky, O., Morrell, M.J., Vogt, B.A., 1995. Contributions of anterior cingulate cortex to behaviour. Brain 118, 279-306.

Drevets, W.C., Price, J.L., Simpson Jr., J.R., Todd, R.D., Reich, T., Vannier, M., Raichle, M.E., 1997. Subgenual prefrontal cortex abnormalities in mood disorders. Nature 386, 824-827

Ekman, P., Friesen, W.V., 1976. Pictures of Facial Affect. Consulting Psychologists Press, Palo Alto, California.

Esteves, F., Ohman, A., 1993. Masking the face: recognition of emotional facial expressions as a function of the parameters of backward masking. Scand. J. Psychol. 34, 1-18.

Etkin, A., Egner, T., Peraza, D.M., Kandel, E.R., Hirsch, J., 2006. Resolving emotional conflict: a role for the rostral anterior cingulate cortex in modulating activity in the amygdala. Neuron 51, 871-882.

Fan, J., Flombaum, J.I., McCandliss, B.D., Thomas, K.M., Posner, M.I., 2003. Cognitive and brain consequences of conflict. Neuroimage 18, 42-57.

Fan, J., McCandliss, B.D., Fossella, J., Flombaum, J.I., Posner, M.I., 2005. The activation of attentional networks. Neuroimage 26, 471-479.

Fan, J., Hof, P.R., Guise, K.G., Fossella, J.A., Posner, M.I., 2008. The functional integration of the anterior cingulate cortex during conflict processing. Cereb. Cortex 18, 796-805.

First, M.B., Spitzer, R.L., Gibbon, M., Williams, J.B.W., 2002. Structured Clinical Interview for DSM-IV-TR Axis I Disorders, Research Version. : Biometrics ResearchNew York State Psychiatric Institute, New York.

Friston, K.J., Fletcher, P., Josephs, O., Holmes, A., Rugg, M.D., Turner, R., 1998. Eventrelated fMRI: characterizing differential responses. Neuroimage 7, 30-40.

Geschwind, N., 1965. Disconnexion syndromes in animals and man. I. Brain 88 , 237-294

Gu, X., Han, S., 2007. Attention and reality constraints on the neural processes of empathy for pain. Neuroimage 36, 256-267.

Gu, X.S., Liu, X., Guise, K.G., Naidich, T.P., Hof, P.R., Fan, J., 2010. Functional dissociation of the frontoinsular and anterior cingulate cortices in empathy for pain. J. Neurosci. 30, 3739-3744.

Hakeem, A.Y., Sherwood, C.C., Bonar, C.J., Butti, C., Hof, P.R., Allman, J.M., 2009. Von Economo neurons in the elephant brain. Anat. Rec. (Hoboken) 292, 242-248.

Hariri, A.R., Bookheimer, S.Y., Mazziotta, J.C., 2000. Modulating emotional responses: effects of a neocortical network on the limbic system. NeuroReport 11, 43-48.

Hariri, A.R., Mattay, V.S., Tessitore, A., Fera, F., Smith, W.G., Weinberger, D.R., 2002a. Dextroamphetamine modulates the response of the human amygdala. Neuropsychopharmacology 27, 1036-1040.

Hariri, A.R., Mattay, V.S., Tessitore, A., Kolachana, B., Fera, F., Goldman, D., Egan, M.F., Weinberger, D.R., 2002b. Serotonin transporter genetic variation and the response of the human amygdala. Science 297, 400-403.

Heinz, A., Braus, D.F., Smolka, M.N., Wrase, J., Puls, I., Hermann, D., Klein, S., Grusser, S.M., Flor, H., Schumann, G., Mann, K., Buchel, C., 2005. Amygdala-prefrontal coupling depends on a genetic variation of the serotonin transporter. Nat. Neurosci. 8, 20-21.

Hof, P.R., Van der Gucht, E., 2007. Structure of the cerebral cortex of the humpback whale, Megaptera novaeangliae (Cetacea, Mysticeti, Balaenopteridae). Anat. Rec. A Discov. Mol. Cell. Evol. Biol. 290, 1-31.

Hoistad, M., Barbas, H., 2008. Sequence of information processing for emotions through pathways linking temporal and insular cortices with the amygdala. Neuroimage 40, 1016-1033.

Jackson, D.C., Malmstadt, J.R., Larson, C.L., Davidson, R.J., 2000. Suppression and enhancement of emotional responses to unpleasant pictures. Psychophysiology 37, 515-522.

Jackson, P.L., Meltzoff, A.N., Decety, J., 2005. How do we perceive the pain of others? A window into the neural processes involved in empathy. Neuroimage 24,771-779.

Kober, H., Barrett, L.F., Joseph, J., Bliss-Moreau, E., Lindquist, K., Wager, T.D., 2008. Functional grouping and cortical-subcortical interactions in emotion: a metaanalysis of neuroimaging studies. Neuroimage 42, 998-1031.

LeDoux, J.E., 2000. Emotion circuits in the brain. Annu. Rev. Neurosci. 23, 155-184.

Li, W., Zinbarg, R.E., Boehm, S.G., Paller, K.A., 2008. Neural and behavioral evidence for affective priming from unconsciously perceived emotional facial expressions and the influence of trait anxiety. J. Cogn. Neurosci. 20, 95-107.

MacDonald III, A.W., Cohen, J.D., Stenger, V.A., Carter, C.S., 2000. Dissociating the role of the dorsolateral prefrontal and anterior cingulate cortex in cognitive control. Science 288, 1835-1838.

Milad, M.R., Quirk, G.J., Pitman, R.K., Orr, S.P., Fischl, B., Rauch, S.L., 2007. A role for the human dorsal anterior cingulate cortex in fear expression. Biol. Psychiatry 62, 1191-1194.

Morgan, M.A., LeDoux, J.E., 1995. Differential contribution of dorsal and ventral medial prefrontal cortex to the acquisition and extinction of conditioned fear in rats. Behav. Neurosci. 109, 681-688.

Morgan, M.A., Romanski, L.M., LeDoux, J.E., 1993. Extinction of emotional learning: contribution of medial prefrontal cortex. Neurosci. Lett. 163, 109-113.

Morris, J.S., Ohman, A., Dolan, R.J., 1998. Conscious and unconscious emotional learning in the human amygdala. Nature 393, 467-470.

Mufson, E.J., Mesulam, M.M., Pandya, D.N., 1981. Insular interconnections with the amygdala in the rhesus monkey. Neuroscience 6, 1231-1248. 
Mutschler, I., Wieckhorst, B., Kowalevski, S., Derix, J., Wentlandt, J., Schulze-Bonhage, A. Ball, T., 2009. Functional organization of the human anterior insular cortex. Neurosci. Lett. 457, 66-70.

Naidich, T.P., Kang, E., Fatterpekar, G.M., Delman, B.N., Gultekin, S.H., Wolfe, D., Ortiz, O. Yousry, I., Weismann, M., Yousry, T.A., 2004. The insula: anatomic study and MR imaging display at $1.5 \mathrm{~T}$. Am. J. Neuroradiol. 25, 222-232.

Nee, D.E., Wager, T.D., Jonides, J., 2007. Interference resolution: insights from a metaanalysis of neuroimaging tasks. Cogn. Affect. Behav. Neurosci. 7, 1-17.

Nimchinsky, E.A., Vogt, B.A., Morrison, J.H., Hof, P.R., 1995. Spindle neurons of the human anterior cingulate cortex. J. Comp. Neurol. 355, 27-37.

Nimchinsky, E.A., Gilissen, E., Allman, J.M., Perl, D.P., Erwin, J.M., Hof, P.R., 1999. A neuronal morphologic type unique to humans and great apes. Proc. Natl Acad. Sci. USA 96, 5268-5273.

Nomura, M., Ohira, H., Haneda, K., Iidaka, T., Sadato, N., Okada, T., Yonekura, Y., 2004 Functional association of the amygdala and ventral prefrontal cortex during cognitive evaluation of facial expressions primed by masked angry faces: an eventrelated fMRI study. Neuroimage 21, 352-363.

Ollinger, J.M., Corbetta, M., Shulman, G.L., 2001a. Separating processes within a trial in event-related functional MRI. II. Analysis. Neuroimage 13, 218-229.

Ollinger, J.M., Shulman, G.L., Corbetta, M., 2001b. Separating processes within a trial in event-related functional MRI. I. The method. Neuroimage 13, 210-217.

Paus, T., 2001. Primate anterior cingulate cortex: where motor control, drive and cognition interface. Nat. Rev. Neurosci. 2, 417-424.

Pegna, A.J., Khateb, A., Lazeyras, F., Seghier, M.L., 2005. Discriminating emotional faces without primary visual cortices involves the right amygdala. Nat. Neurosci. 8, 24-25.

Phan, K.L., Wager, T., Taylor, S.F., Liberzon, I., 2002. Functional neuroanatomy of emotion: a meta-analysis of emotion activation studies in PET and fMRI. Neuroimage 16, 331-348.

Phelps, E.A., O'Connor, K.J., Gatenby, J.C., Gore, J.C., Grillon, C., Davis, M., 2001. Activation of the left amygdala to a cognitive representation of fear. Nat. Neurosci. 4, 437-441.

Phelps, E.A., Delgado, M.R., Nearing, K.I., LeDoux, J.E., 2004. Extinction learning in humans: role of the amygdala and vmPFC. Neuron 43, 897-905.

Price, J.L., Amaral, D.G., 1981. An autoradiographic study of the projections of the central nucleus of the monkey amygdala. J. Neurosci. 1, 1242-1259.

Rao, H., Korczykowski, M., Pluta, J., Hoang, A., Detre, J.A., 2008. Neural correlates of voluntary and involuntary risk taking in the human brain: an fMRI Study of the Balloon Analog Risk Task (BART). Neuroimage 42, 902-910.

Ruge, H., Goschke, T., Braver, T.S., 2009. Separating event-related BOLD components within trials: the partial-trial design revisited. Neuroimage 47, 501-513.

Sanfey, A.G., 2007. Social decision-making: insights from game theory and neuroscience. Science 318, 598-602.
Schulz, K.P., Clerkin, S.M., Halperin, J.M., Newcorn, J.H., Tang, C.Y., Fan, J., 2009 Dissociable neural effects of stimulus valence and preceding context during the inhibition of responses to emotional faces. Hum. Brain Mapp. 30, 2821-2833.

Seeley, W.W., Menon, V., Schatzberg, A.F., Keller, J., Glover, G.H., Kenna, H., Reiss, A.L Greicius, M.D., 2007. Dissociable intrinsic connectivity networks for salience processing and executive control. J. Neurosci. 27, 2349-2356.

Sheline, Y.I., Barch, D.M., Donnelly, J.M., Ollinger, J.M., Snyder, A.Z., Mintun, M.A., 2001 Increased amygdala response to masked emotional faces in depressed subjects resolves with antidepressant treatment: an fMRI study. Biol. Psychiatry 50, 651-658.

Singer, T., Seymour, B., O'Doherty, J., Kaube, H., Dolan, R.J., Frith, C.D., 2004. Empathy for pain involves the affective but not sensory components of pain. Science 303 , 1157-1162.

Singer, T., Critchley, H.D., Preuschoff, K., 2009. A common role of insula in feelings, empathy and uncertainty. Trends Cogn. Sci. 13, 334-340.

Slotnick, S.D., Schacter, D.L., 2004. A sensory signature that distinguishes true from false memories. Nat. Neurosci. 7, 664-672.

Tessitore, A., Hariri, A.R., Fera, F., Smith, W.G., Chase, T.N., Hyde, T.M., Weinberger, D.R., Mattay, V.S., 2002. Dopamine modulates the response of the human amygdala: a study in Parkinson's disease. J. Neurosci. 22, 9099-9103.

Tsuchiya, N., Moradi, F., Felsen, C., Yamazaki, M., Adolphs, R., 2009. Intact rapid detection of fearful faces in the absence of the amygdala. Nat. Neurosci. 12, 1224-1225.

Tzourio-Mazoyer, N., Landeau, B., Papathanassiou, D., Crivello, F., Etard, O., Delcroix, N., Mazoyer, B., Joliot, M., 2002. Automated anatomical labeling of activations in SPM using a macroscopic anatomical parcellation of the MNI MRI single-subject brain. Neuroimage 15, 273-289.

Vogt, B.A., Finch, D.M., Olson, C.R., 1992. Functional heterogeneity in cingulate cortex: the anterior executive and posterior evaluative regions. Cereb. Cortex 2, 435-443.

Von Economo, C., Koskinas, G., 1925. Die Cytoarchitectonik der Hirnrinde des erwachsenen. Menschen Springer, Berlin.

Vuilleumier, P., Armony, J.L., Driver, J., Dolan, R.J., 2001. Effects of attention and emotion on face processing in the human brain: an event-related fMRI study. Neuron 30 , 829-841.

Whalen, P.J., Kagan, J., Cook, R.G., Davis, F.C., Kim, H., Polis, S., McLaren, D.G., Somerville, L.H., McLean, A.A., Maxwell, J.S., Johnstone, T., 2004. Human amygdala responsivity to masked fearful eye whites. Science 306, 2061.

Williams, J.M., Mathews, A., MacLeod, C., 1996. The emotional Stroop task and psychopathology. Psychol. Bull. 120, 3-24.

Worsley, K.J., Marrett, S., Neelin, P., Vandal, A.C., Friston, K.J., Evans, A.C., 1996. A unified statistical approach for determining significant signals in images of cerebral activation. Hum. Brain Mapp. 4, 58-73. 